\title{
Preparation of chiral isoxazole carbinols via catalytic asymmetric Corey-Bakshi-Shibata reduction
}

\author{
Kevin C. Rider, ${ }^{\text {a,b }}$ David J. Burkhart, ${ }^{\text {a,c }}$ Chun Li, ${ }^{\text {a,d }}$ Andrew R. McKenzie, ${ }^{\text {a,e }}$ \\ Jared K. Nelson, ${ }^{a, f}$ and Nicholas R. Natale ${ }^{\mathrm{a}, \mathrm{b}_{*}}$ \\ ${ }^{a}$ Department of Chemistry, University of Idaho, Moscow ID 83844-2343 ${ }^{b}$ Center for Structural \\ and Functional Neuroscience, Department of Biomedical and Pharmaceutical Sciences, The \\ University of Montana, Missoula MT 59812 \\ Current addresses: ' GSK Biologicals, 553 Old Corvallis Rd., Hamilton MT 59840, \\ ${ }^{d}$ Ithaca College, Department of Chemistry, 355 Center for Natural Sciences, Ithaca NY 14850 \\ ${ }^{e}$ AstraZeneca R\&D Boston, 35 Gatehouse Dr., Waltham, MA 0245, ${ }^{f}$ PharmAgra Labs, \\ 158 McClean Rd., Brevard, NC 28712 \\ E-mail: nicholas.natale@umontana.edu
}

\begin{abstract}
Dedicated in Honor of Dr. Bruce E. Maryanoff and Dr. Cynthia A. Maryanoff on the occasion of their outstanding contributions to organic chemistry as industrial chemists
\end{abstract}

\begin{abstract}
A diverse set of isoxazoles, with activity in three different disease categories, was reduced asymmetrically from pro-chiral ketones to chiral alcohols using the Corey-Bakshi-Shibata methodology at the $\alpha, \beta$, and $\gamma$ positions relative to the C-5-methyl of the isoxazole. The experiments described provide an easy route to hydroxylated isoxazoles that represent the common CYP-450 3A4 metabolic site.
\end{abstract}

Keywords: Asymmetric synthesis, catalysis, isoxazole, oxazaborolidine, reduction

\section{Introduction}

Isoxazoles have found continuing application in medicinal chemistry, several examples of which have advanced to general medical practice. ${ }^{1}$ As potential new chemical entities advance from in vitro screening through in vivo study towards clinical trials, pharmacokinetic properties collectively referred to as ADMET for Absorption, Distribution, Metabolism, Excretion and Toxicity $^{2}$ - become important considerations: half of drug attrition can be attributed to poor ADMET properties. An interesting facet of the biology of isoxazoles is that one significant route of metabolism and excretion is C-5 methyl hydroxylation, ${ }^{3}$ mediated by the cytochrome P450 
isoform $3 \mathrm{~A} 4,{ }^{4}$ often followed by conjugation to the glucuronide. ${ }^{5}$ The existence of a safe route for drug metabolism is an important design feature for potential investigational new drugs containing the isoxazole. Our own interest in the biological activity of several classes of isoxazoles $^{6-8}$ required access into isoxazole carbinols in chiral form for metabolic fate experiments.

Our initial attempts used an extension of our previous studies on the lateral metalation and electrophilic quenching of isoxazoles ${ }^{9-10}$ into the realm of asymmetric catalysis. ${ }^{11,12}$ Over fifty attempts employing chiral bis-oxazolines, ${ }^{13}$ Shibasaki's lanthanum BINOL, ${ }^{14}$ Jacobsen's salen aluminum catalyst ${ }^{15}$ and Sparteine, ${ }^{16}$ in the lateral metalation reaction failed to produce a significant enantio-enrichment of the product.

We sought an alternate route which would provide synthetically useful results, and now report that the use of the Corey-Bakshi-Shibata $(\mathrm{CBS})^{17}$ reduction on isoxazolyl ketones produces chiral isoxazolyl carbinols in uniformly excellent chemical yields with high enantiocontrol in many cases.

\section{Results and Discussion}

The racemic alcohols 1a-j were prepared using lateral metalation as previously described: $\alpha$ hydroxyls were prepared by lateral metalation followed by quenching with the Davis oxaziridine, ${ }^{18} \beta$-hydroxyls were prepared by quenching with the appropriate aldehyde, ${ }^{10 \mathrm{~b}, \mathrm{c}}$ and the $\gamma$-hydroxyl example was prepared by ring opening of styrene. ${ }^{19}$ The ketones $\mathbf{2 a - j}$ were then prepared by oxidation using the Dess-Martin Periodinane reagent. ${ }^{20}$

The reductions illustrated in Scheme 1 were typically carried out at $-45^{\circ} \mathrm{C}$ in dichloromethane, monitored by TLC until consumption of the ketone, and the chemical yields were uniformly very good to excellent. The enantiomeric excess was determined by HPLC-CSP and the results are summarized in Chart 1. The absolute configuration of (S)-3a was established by comparison of optical rotation to (R)-3a established by single crystal X-ray diffractometry using anomalous scattering techniques on a derived chloro-phenylisoxazolo[3,4-d]pyridazinone as previously described. ${ }^{12}$ The absolute configuration of $(\mathrm{S})-\mathbf{3} \mathbf{j}$, produced by reduction with $(R)-$ (-)-2-(diphenylhydroxymethyl)-pyrrolidine ((R)-diphenyl-prolinol), which was established by its optical rotation by comparison to known (S)-3j, established via epoxide ring opening with retention from $(R)$-styrene oxide. ${ }^{19}$ The remaining configurations were established by the order of elution via chiral HPLC-CSP. The stereochemical outcome appears to be consistent with the Corey transition state model. ${ }^{17}$ High enantioselectivities were observed for aryl-alkyl ketones $\mathbf{3 j}$ ( $89 \%$ e.e.), $3 \mathbf{g}$ ( $97 \%$ e.e.), $3 \mathbf{h}$ ( $99 \%$ e.e.), where the discriminating factor during the reduction is essentially analogous to acetophenone, ${ }^{17 \mathrm{c}}$ and the isoxazolyl function is removed from the reduction site. The $p$-chlorophenyl compound $3 \mathbf{h}$ produced virtually enantiopure material. As the isoxazolyl function increases in functional complexity and presents potential competing chelating groups, the e.e. is observed to erode slightly as in example 6 ( $80 \%$ e.e.). For the case of 
the dihydropyridine $\mathbf{3}$, two equivalents of borane are necessary to effect conversion to alcohol, and a plethora of potential lone pairs, as well as conformational flexibility, "confuse" the situation, resulting in significantly lower stereoselectivity $(47 \%$ e.e.). Thus, a complex interplay of both steric and electronic factors affects the selectivity. Steric factors alone do not appear to affect the outcome if the large group is more than one methylene removed from the ketone: in example 3e, where the local environment at the ketone presents a methyl versus a methylene, produced almost no induction, despite the presence of the dirigible-like anthracene-isoxazole moiety nearby.

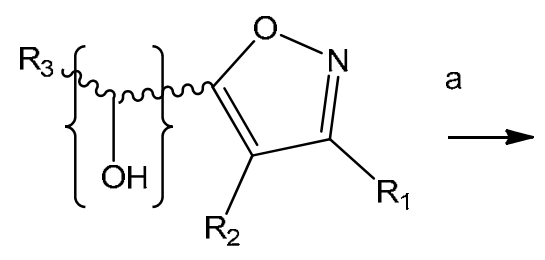

1

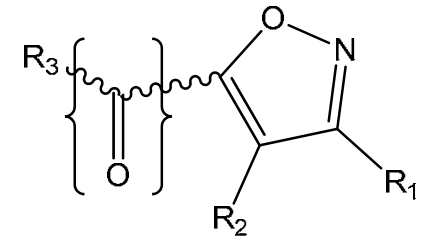

2

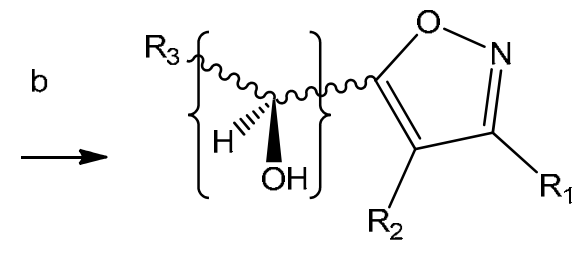

3

Scheme 1. Dess-Martin periodinane (DMP), $\mathrm{CH}_{2} \mathrm{Cl}_{2}$. (b) $\mathrm{BH}_{3}$.DMS, 10-20 mol.\% (R)-diphenylprolinol, $-45^{\circ} \mathrm{C}, \mathrm{CH}_{2} \mathrm{Cl}_{2}$. 

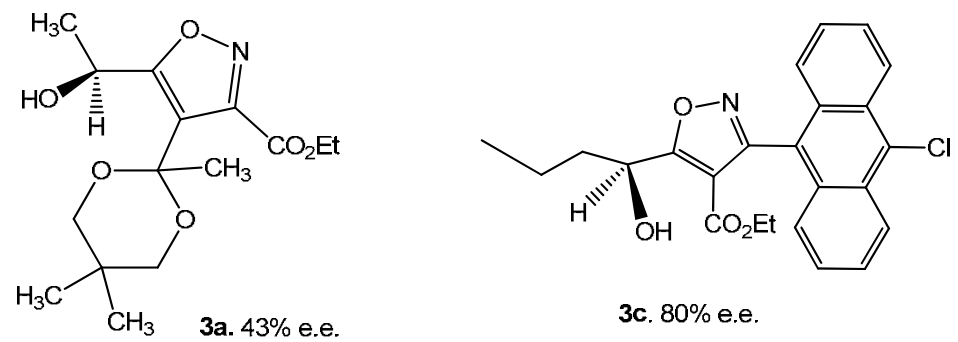

3c. $80 \%$ e.e.

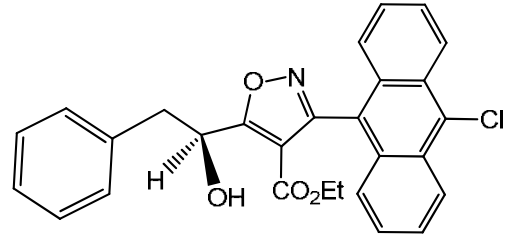

3d. $72-82 \%$ e.e

3b. $72-75 \%$ e.e.
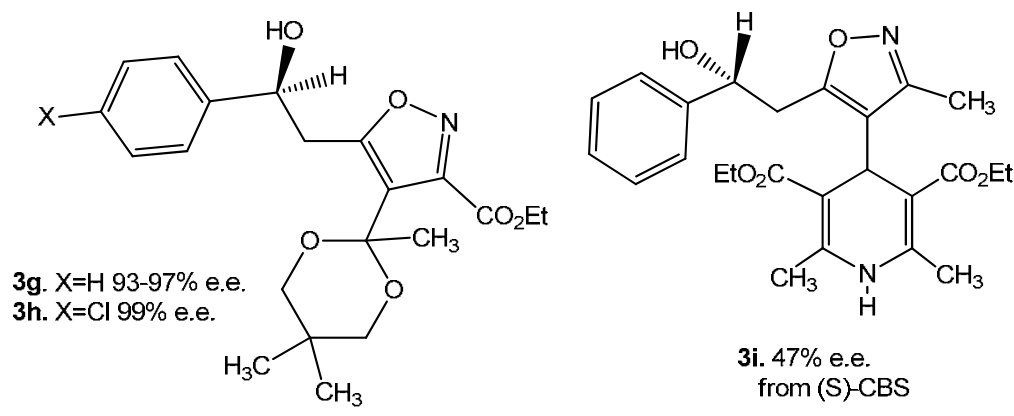

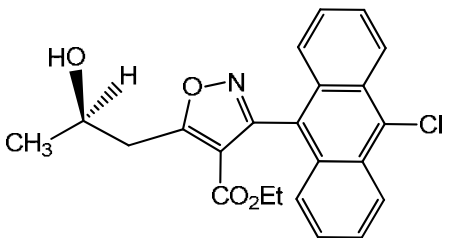

3e. $0 \%$ e.e

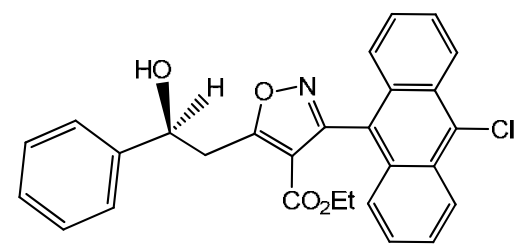

3f. $82 \%$ e.e

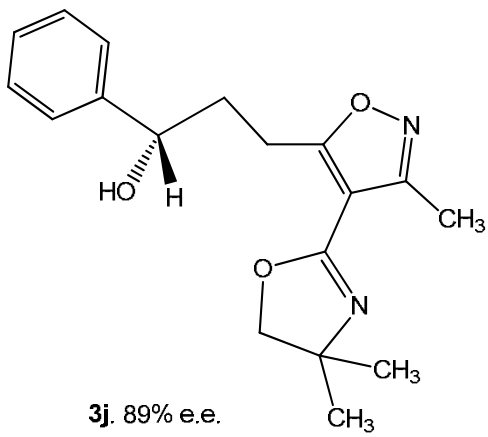

Chart 1. Enantioselectivity in the CBS reduction of isoxazolyl-ketones at 20 mole \% CBS loading, measured by HPLC-CSP using either Chiralpak AD or Chiralcel OJ, 40:1 hexanes: EtOH. The (R)-CBS-oxazaborolidine was used unless otherwise noted.

The standard experiments were conducted at 20 mole \% catalyst loading, although the enantiomeric excess was not dramatically affected in the case of $\mathbf{3 g}$ by lowering the amount of chiral oxazaborolidine to 10 mole \%: the chemical yield was not affected (93 versus $92 \%$ yield), and only a slight change in the e.e. was noted (97 to $93 \%$ e.e.). This was also true for example $3 \mathbf{b}$, where 10 mole $\%$ chiral catalyst produced almost identical yield and stereoselectivity (76 versus $74 \%$ yield, identical $72 \%$ e.e.). Unfortunately, for the cases with lower e.e., for example 3b, raising the catalyst loading from 20 to 80 mole \% showed virtually no effect on yield (74 versus $73 \%$ chemical yield), but the large increase in chiral catalyst produced only a slight increase in e.e., that might be within experimental error (raised only to 75 from $72 \%$ e.e.).

In the remaining four examples the isoxazole represents the aryl group, and in the case where the small group is methyl the e.e. is lowest 3a, $(43 \%$ e.e.). In the remaining three cases the e.e.'s are higher, $3 \mathbf{b}-\mathbf{d}(72-82 \%$ e.e.) which may be consistent with the ability to adopt similar major conformations vis-a-vis the keto isoxazoles 2 which led to conformational restriction during the 
critical hydride delivery. However, there is another possibility in that these ketones are easily enolizable, as evidenced by the X-ray structure of the enol corresponding to $2 \mathbf{d}^{22}$, which we postulated could influence the reaction course. Therefore we examined the reactions for $3 \mathbf{d}$ in more detail. There was a noticeable solvent effect, as dichloromethane ( $72 \%$ e.e.) produced slightly higher e.e. than THF (63\% e.e.). In THF we also noticed a pronounced aging effect, that is, over the course of standing the e.e. was observed to erode, in one experiment conducted at $-45{ }^{\circ} \mathrm{C}$ from $83 \%$ e.e. at 18 hours and incomplete conversion, to $64 \%$ e.e. at 66 hours. The aging effect was even more pronounced at higher temperature, where the initial $82 \%$ e.e. at 20 hours eroded to $39 \%$ e.e. at $-20^{\circ} \mathrm{C}$ over 110 hours. Our explanation for the aging of the e.e. for $3 \mathbf{d}$ may be a Meerwein-Ponndorf-Verley reduction / Oppenauer oxidation type disproportionation, which leads to racemization over time.

\section{Conclusions}

We have shown that CBS-oxazaborolidine can be used to reduce C5-isoxazolyl-ketones under conditions that optimize chemical yield and enrich enantio-purity. Our results are consistent with Corey's transition state model and show selectivity, as the method gives the corresponding opposite enantiomer from that of the catalyst used [i.e., (R)-CBS give (S)]. The solvent effects we observed in attrition of \% e.e. can possibly be explained by the enolizability of the starting ketone corresponding with reaction solvent - THF is poor when compared to methylene chloride - and time, though it appears that a small amount of THF is tolerated as $\mathbf{3 b}$ was separately synthesized using reagent dimethyl sulfide /borane complex in THF and $\mathrm{CH}_{2} \mathrm{Cl}_{2}$, and the \% e.e. was unchanged. Temperature had little effect on chemical yield, but a pronounced effect on final enantio-enrichment when THF was used as the reaction solvent, making $-45^{\circ} \mathrm{C}$ the optimal temperature for this series of reactions, as it was easily maintained over the usual 24 hour reaction time.

The results of this study have allowed us to continue our work with isoxazole functionalization of the C-5 position of the ring, such that we are now able to introduce hydroxyl groups in the $\alpha-, \beta-$ and $\gamma-$ positions to the isoxazole, that will aid in future metabolic studies of our compounds with CYP-450 3A4 - the predicted isozyme for isoxazole metabolism as based on literature precedent. This methodology not only allows access to the CYP-450 3A4 potential metabolites but the added element of chirality can be explored in both the activity of the hydroxy-isoxazole in its corresponding disease area and bio-availability, thus allowing exploration of the ADMET profile of these compounds. We will report on our progress in due course. 


\section{Experimental Section}

General. Mass spectra were obtained on a JEOL JMS-AX505 HA. NMR spectra $\left({ }^{1} \mathrm{H}-\right.$ and $\left.{ }^{13} \mathrm{C}-\right)$ were obtained on a Bruker Avance 300 Digital NMR (300 MHz) using SGI-IRIX 6.5. Elemental analyses were performed by Desert Analytics Laboratory, PO Box 41838, Tucson, Arizona 85717. All reactions were performed under argon atmosphere. Tetrahydrofuran was distilled from sodium-benzophenone immediately before use. Dichloromethane was freshly distilled from $\mathrm{P}_{2} \mathrm{O}_{5}$ before use. The Dess-Martin reagent was synthesized according to literature methods ${ }^{21}$ and stored under argon in a freezer. Radial chromatography was performed on silica gel (Merck 60 A, 230-400mesh). Ethyl 3-(10'chloro-9'-anthracenyl)-5-methyl-4-isoxazolecarboxylate and ethyl 3-(10'-chloro-9'-anthracenyl)-5-phenylethyl-4-isoxazolecarboxylate were synthesized via the routes developed by our laboratory. ${ }^{10 \mathrm{c}, 18 \mathrm{~b}}$ Compound $3 \mathrm{f}$ has been characterized in racemic form. ${ }^{10 \mathrm{c}}$

\section{General procedure for the Dess-Martin oxidation of isoxazolyl alcohols}

To an oven- dried round bottom flask $(50 \mathrm{~mL})$ was added $2.3 \mathrm{~g}(11.5 \mathrm{mmol})$ of the isoxazole alcohol and a magnetic stir bar, under a $\mathrm{N}_{2}$ atmosphere. Freshly distilled dichloromethane $(40 \mathrm{~mL})$ was added and the solution stirred until the isoxazole alcohol completely dissolved. Dess-Martin periodinane (4.87g, 1.0 eq.) was added in one portion and the solution stirred for 23 hours: the reaction progress was monitored by TLC. After TLC analysis indicated depletion of the starting alcohol, the reaction was concentrated under vacuum and diluted with diethyl ether $(100 \mathrm{~mL})$. The periodinane by-product which precipitates is then filtered and the ether solution combined with $25 \mathrm{~mL}$ saturated $\mathrm{NaHCO}_{3}$, and $25 \mathrm{~mL}$ of saturated sodium sulfide in a $250 \mathrm{~mL}$ flask. The biphasic mixture is stirred vigorously for 15 minutes and then transferred to a separatory funnel. The organic phase is separated, washed with brine $(25 \mathrm{~mL})$, dried with anhydrous sodium sulfate, and concentrated. Purity was determined by ${ }^{1} \mathrm{H}-\mathrm{NMR}$ and the compounds purified by column chromatography (Hex: EtOAc) on silica gel if necessary. Final compounds were fully characterized by ${ }^{1} \mathrm{H} \mathrm{NMR},{ }^{13} \mathrm{C} \mathrm{NMR}$, and elemental analysis or accurate mass determination. Complete characterization has been reported for $\mathbf{2} \mathbf{b}, \mathbf{2} \mathbf{g}, \mathbf{2} \mathbf{i}$ and $\mathbf{2} \mathbf{j}$. ${ }^{20}$

Ethyl 5-acetyl-4-(5,5-dimethyl-1,3-dioxan-2-yl)isoxazole 3-carboxylate 2a. Purified by radial chromatography using hexanes: EtOAc $(5: 1)$ to afford $53 \mathrm{mg}$ of $\mathbf{2 a}, 93 \%$ yield. ${ }^{1} \mathrm{H}$ NMR $\delta 0.68$ $(\mathrm{s}, 3 \mathrm{H}), 1.19(\mathrm{~s}, 3 \mathrm{H}), 1.41$ (t, 3H, J=7.1 Hz), 1.79 (s, 3H), 2.69 (s, 3H), 3.34 (m, 4H), 4.45 (q, 2H, $\mathrm{J}=7.1 \mathrm{~Hz}$ ). Accurate mass: Calculated for $\mathrm{C}_{15} \mathrm{H}_{22} \mathrm{NO}_{6}: 312.1447$. Found: 312.1435 .

Ethyl 5-butanoyl-3-(10-chloro-9-anthryl)isoxazole-4-carboxylate 2c. Yellow solid from hexane-ethyl acetate $(6: 1), \mathrm{mp} 85.5{ }^{\circ} \mathrm{C} ;{ }^{1} \mathrm{H}-\mathrm{NMR}\left(\mathrm{CDCl}_{3}\right): \delta(\mathrm{ppm}) 0.57(\mathrm{t}, \mathrm{J}=7.1 \mathrm{~Hz}, 3 \mathrm{H}), 1.13$ $(\mathrm{t}, \mathrm{J}=7.3 \mathrm{~Hz}, 3 \mathrm{H}), 1.94(\mathrm{~m}, 2 \mathrm{H}), 3.20$ (t, J=7.1Hz, 2H), 3.85 (q, J=7.1Hz, 2H), $7.53(\mathrm{~m}, 2 \mathrm{H}), 7.65$ $(\mathrm{m}, 4 \mathrm{H}), 8.62(\mathrm{~d}, \mathrm{~J}=8.4 \mathrm{~Hz}, 2 \mathrm{H}) ;{ }^{13} \mathrm{C}-\mathrm{NMR}\left(\mathrm{CDCl}_{3}\right): \delta(\mathrm{ppm}) 12.95,13.57,16.73,43.25,61.48$, 116.32, 120.30, 125.21, 125.50, 126.86, 127.00, 128.35, 131.19, 131.96, 159.82, 160.57, 166.79, 189.97; MS (EI): m/z $421.20\left(\mathrm{M}^{+}, 100 \%\right), 350.10$ (13.17\%), 322.10 (15.08\%), 277.05 (22.31\%), 
236.95 (12.21\%), 214.05 (13.52\%), 176.05 (10.96\%). Anal. Calcd. for $\mathrm{C}_{24} \mathrm{H}_{20} \mathrm{NO}_{4} \mathrm{Cl}$ : C, 68.33; H, 4.78; N, 3.32. Found: C, 68.19; H, 4.82; N, 3.38\%.

Ethyl 3-(10'-chloro-9'-anthracenyl)-5-phenylacetyl-4-isoxazolecarboxylate 2d. Yellow solid from hexane-ethyl acetate (6:1), mp 134-135 ${ }^{\circ} \mathrm{C} ;{ }^{1} \mathrm{H}-\mathrm{NMR}\left(\mathrm{CDCl}_{3}\right): \delta(\mathrm{ppm}) 0.55(\mathrm{t}, \mathrm{J}=7.1 \mathrm{~Hz}$, 3H), $3.81(\mathrm{q}, \mathrm{J}=7.1 \mathrm{~Hz}, 2 \mathrm{H}), 4.49(\mathrm{~s}, 1 \mathrm{H}), 7.42(\mathrm{~m}, 4 \mathrm{H}), 7.54(\mathrm{~m}, 4 \mathrm{H}), 7.65(\mathrm{~m}, 3 \mathrm{H}), 8.62(\mathrm{~d}$, $\mathrm{J}=8.4 \mathrm{~Hz}, 2 \mathrm{H}) ;{ }^{13} \mathrm{C}-\mathrm{NMR}\left(\mathrm{CDCl}_{3}\right): \delta$ (ppm) 12.94, 48.08, 61.47, 116.71, 120.17, 125.19, 125.45, 126.84, 126.99, 127.67, 128.32, 128.92, 129.93, 131.15, 131.74, 131.90, 159.62, 160.51, 166.63, 187.55; MS (EI): $\mathrm{m} / \mathrm{z} 469.20$ (M+100\%), 350.10 (11.24\%), 322.10 (14.49\%), 277.05 (36.36\%), 214.10 (13.23\%), 176.10 (17.76\%), 91.05 (15.78\%). Anal. Calcd. for $\mathrm{C}_{28} \mathrm{H}_{20} \mathrm{NO}_{4} \mathrm{Cl}: \mathrm{C}, 71.57 ; \mathrm{H}$, 4.29; N, 2.98. Found: C, 70.84; H, 4.39; N, 2.90\%.

Ethyl 3-(10-chloro-9-anthracenyl)-5-(2-oxo-2-methyl)isoxazole-4-carboxylate 2e. Yield 98\%, m.p. $115-117^{\circ} \mathrm{C},{ }^{1} \mathrm{H}$ NMR $\left(\mathrm{CDCl}_{3}\right) \delta 8.6(\mathrm{~d}, 2 \mathrm{H}), 7.69-7.61(\mathrm{~m}, 4 \mathrm{H}), 7.54-7.50(\mathrm{~m}, 2 \mathrm{H}), 4.48(\mathrm{~s}$, $2 \mathrm{H}), 3.7(\mathrm{q}, \mathrm{J}=7.2 \mathrm{~Hz}, 2 \mathrm{H}), 2.45(\mathrm{~s}, 3 \mathrm{H}), 0.35(\mathrm{t}, \mathrm{J}=7.2,3 \mathrm{H}) ;{ }^{13} \mathrm{C}$ NMR $173.48,162.53$, 132.04, 129.33, 129.18, 127.61, 126.67, 126.25, 126.15, 125.94, 61.28, 42.84, 31.10, 13.68; MS (EI) $\mathrm{m} / \mathrm{z}$ 69(10.85), 174(10.24), 175(10.97), 176(35.22), 177(9.93), 190(10.11), 201(13.14), 203(13.28), 212(15.42), 213(11.46), 214(36.54), 215(18.69), 216(9.99), 224(10.77), 225(11.11), 226(15.10), 227(19.71), 228(14.60), 237(30.08), 238(11.13), $239(14.28), \quad 243(13.25)$, 250(14.06), 251(11.65), 253(24.38), 262(15.36), 277(36.96), 278(17.45), 279(19.87), 322(10.41), 373(22.16), $407 \quad\left(\mathrm{C}_{23} \mathrm{H}_{18}{ }^{35} \mathrm{ClNO}_{4}, \quad 100, \quad \mathrm{M}^{+}\right), \quad 408\left(34.72, \quad(\mathrm{M}+1)^{+}\right), \quad 409$ $\left(\mathrm{C}_{23} \mathrm{H}_{18}{ }^{37} \mathrm{ClNO}_{4}, 43.14,(\mathrm{M}+2)^{+}\right)$.

Ethyl 3-(10-chloro-9-anthracenyl)-5-(2-oxo-2-phenethyl)isoxazole-4-carboxylate 2f. Yield 95\%, m.p. $105-107^{\circ} \mathrm{C},{ }^{1} \mathrm{H}$ NMR $\left(\mathrm{CDCl}_{3}\right) \delta 8.53(\mathrm{~d}, 2 \mathrm{H}), 8.03(\mathrm{~d}, 2 \mathrm{H}), 7.64-7.42(\mathrm{~m}, 9 \mathrm{H}), 4.97(\mathrm{~s}$, 2H), $3.6(\mathrm{q}, \mathrm{J}=7.2 \mathrm{~Hz}, 2 \mathrm{H}), 0.23(\mathrm{t}, \mathrm{J}=7.2 \mathrm{~Hz}, 3 \mathrm{H}) ;{ }^{13} \mathrm{C}$ NMR $\delta$ 192.88, 173.85, 161.74, 160.96, 136.66, 134.82, 132.00, 131.97, 129.77, 129.23, 129.18, 129.11, 127.54, 127.52, 126.69, 125.83, 122.99, 114.10, 61.16, 38.62, 31.10, 30.49, 21.85, 14.99, 13.60; MS (EI) m/z 77 (17.74), 105 (63.23), 176 (11.07), 205 (45.29), 220 (15.52), 237 (19.05), 253 (11.79), $469\left(\mathrm{C}_{28} \mathrm{H}_{20}{ }^{35} \mathrm{ClNO}_{4}\right.$, $\left.100, \mathrm{M}^{+}\right), 470\left(34.36,(\mathrm{M}+1)^{+}\right), 471\left(\mathrm{C}_{28} \mathrm{H}_{20}{ }^{37} \mathrm{ClNO}_{4}, 40.26,(\mathrm{M}+2)^{+}\right)$.

Ethyl 5-[2-(4-chlorophenyl)-2-oxo-ethyl]-4-(2,5,5-trimethyl-1,3-dioxan-2-yl)-isoxazole-3carboxylate $2 \mathrm{~h}$. Yield $89 \%$, colorless solid, m.p. $=53-54{ }^{\circ} \mathrm{C}{ }^{1} \mathrm{H}-\mathrm{NMR} \delta 0.66(\mathrm{~s}, 3 \mathrm{H}), 1.42(\mathrm{~s}$, $3 \mathrm{H}), 1.38(\mathrm{t}, \mathrm{J}=4.2 \mathrm{~Hz}, 3 \mathrm{H}), 1.66(\mathrm{~s}, 3 \mathrm{H}), 3.34(\mathrm{~m}, 4 \mathrm{H}), 4.42(\mathrm{q}, \mathrm{J}=4.2 \mathrm{~Hz}, 2 \mathrm{H}), 4.52(\mathrm{~s}, 2 \mathrm{H})$, $7.48(\mathrm{~d}, \mathrm{~J}=5.1 \mathrm{~Hz}, 2 \mathrm{H}) 7.92(\mathrm{~d}, \mathrm{~J}=5.1 \mathrm{~Hz}, 2 \mathrm{H}) ;{ }^{13} \mathrm{C}-\mathrm{NMR} 14.4,22.3,22.8,29.9,30.3,36.4$, 62.9, 72.2, 96.7, 117.3, 128.8, 129.3, 134.3, 136.3, 156.7, 161.9, 164.7, 193.0; Formula weight for $\mathrm{C}_{21} \mathrm{H}_{24} \mathrm{O}_{6} \mathrm{NCl}$, Calculated 421.13: Accurate mass was done for the M-15 peak 406. The intensity of the molecular ion peak at $\mathrm{m} / \mathrm{z} 421$ was too low for accurate mass measurement at 5000 resolution. Calculated for $\mathrm{C}_{20} \mathrm{H}_{21} \mathrm{NO}_{6} \mathrm{Cl}$ 406.1057; Found 406.1061. 


\section{General procedure for the asymmetric reduction of isoxazolyl aryl ketones}

To an oven dried round- bottomed flask and magnetic stir bar was added $2 \mathrm{~mL}$ dry $\mathrm{CH}_{2} \mathrm{Cl}_{2}$, and $0.154 \mathrm{~mL}$ of (R)-2-methyl-CBS-oxazaborolidine ( $1 M$ in toluene), followed quickly by $0.385 \mathrm{~mL}$ dimethyl sulfide borane $\left(2 \mathrm{M}\right.$ in THF or $\mathrm{CH}_{2} \mathrm{Cl}_{2}$ ). The reaction was quickly cooled to $-45{ }^{\circ} \mathrm{C}$ under a passive Ar atmosphere. Isoxazole ketone $(0.3 \mathrm{~g}, 0.77 \mathrm{mmol})$ was dissolved in $1 \mathrm{~mL}$ dry $\mathrm{CH}_{2} \mathrm{Cl}_{2}$ in a separate round bottom flask. The ketone solution was slowly added to the borane solution over a period of 30 minutes. The reaction was maintained at $-45{ }^{\circ} \mathrm{C}$ with stirring and allowed to react until completion ( 24 hours), as determined by TLC. The reaction was quenched by the addition of $5 \mathrm{~mL} \mathrm{MeOH}$ and concentrated. Purification by column chromatography (Hex: EtOAc) gave the chiral alcohols in pure form. Enantiomeric excess was determined by CSP HPLC using a Chiracel OJ or AS column (Hex: EtOH, 40:1).

For compounds 3c-3f, reduction progress was monitored by HPLC, using a Chiralpak AD column and hexane-EtOH $(40: 1$ or $12: 1)$ as the eluting solvent, $\lambda=254 \mathrm{~nm}$. The $\%$ e.e. was calculated based on the ratio of the enantiomers. See Chart 1 for the HPLC-CSP ratios.

\section{Synthesis of ethyl 5-[1-hydroxyethyl]-4-(2,5,5-trimethyl-1,3-dioxan-2-yl)isoxazole-3-} carboxylate (S)-3a. An oven- dried round bottomed flask $(25 \mathrm{~mL})$ was charged with $8 \mathrm{~mL}$ freshly distilled $\mathrm{CH}_{2} \mathrm{Cl}_{2}$, and a magnetic stir bar at room temperature under an argon atmosphere with a passive flow setup. $(R)$-2-Methyl-CBS-oxazaborolidine $(0.2$ equiv., $0.037 \mathrm{mmol}, 1.0 \mathrm{M}$ in toluene, $0.037 \mathrm{~mL}$ ) was added to the flask via a gas-tight syringe, followed by addition of borane dimethyl sulfide (1.1 equivalents, $0.205 \mathrm{mmol}, 1.0 \mathrm{M}$ in $\mathrm{CH}_{2} \mathrm{Cl}_{2}, 0.205 \mathrm{~mL}$ ) via a gas-tight syringe. This catalyst solution was then immediately cooled to $-40^{\circ} \mathrm{C}$ in a dry ice/acetonitrile bath. The ketone $(0.186 \mathrm{mmol}, 58 \mathrm{mg})$ was taken up in about $1 \mathrm{~mL}$ of $\mathrm{CH}_{2} \mathrm{Cl}_{2}$, and transferred to the catalyst solution dropwise over $1 \mathrm{hr}$. The solution was allowed to stir at $-40^{\circ} \mathrm{C}$ for $8-10 \mathrm{hrs}$, and warmed over $1 \mathrm{hr}$. Spectroscopic data were identical with those of racemic $3 \mathbf{a}^{12}$ HPLC separation on a chiral stationary phase (Chiracel AS column, $254 \mathrm{~nm}$ detector, $1 \mathrm{ml} / \mathrm{min}, 30: 1$ hexanes: $\mathrm{EtOH}$ ) showed that the product had a $43 \%$ enantiomeric excess.

Ethyl 5-[hydroxy-2-phenyl-ethyl]-4-(2,5,5-trimethyl-1,3-dioxan-2-yl)isoxazole-3-carboxyl ate 3b. Colorless oil, $[\alpha]_{\mathrm{D}}{ }^{25}=+49.0^{\circ},\left[c=1.0, \mathrm{CH}_{2} \mathrm{Cl}_{2}\right]{ }^{1} \mathrm{H}-\mathrm{NMR} 0.55(\mathrm{~s}, 3 \mathrm{H}), 1.05(\mathrm{~s}, 3 \mathrm{H}), 1.33$ $(\mathrm{t}, 3 \mathrm{H}), 3.09$ (d, J=11Hz, 2H), $3.20(\mathrm{~d}, J=11 \mathrm{~Hz}, 2 \mathrm{H}), 4.33$ (q, 2H), 5.09 (t, 1H), 7.08-7.24 (m, 5H); ${ }^{13} \mathrm{C}-\mathrm{NMR} 14.4,22.2,22.7,29.7,30.1,42.5,63.0,67.9,72.2,72.3,96.7,116.3,127.5$, 129.1, 129.9, 136.6, 156.6, 161.8, 170.0.

Ethyl 3-(10-chloro-9-anthryl)-5-[1-hydroxybutyl]isoxazole-4-carboxylate 3c. A pale yellow solid, crystallized from hexanes-ethyl acetate (10:1), mp 90-92 ${ }^{\circ} \mathrm{C} ;{ }^{1} \mathrm{H}-\mathrm{NMR}\left(\mathrm{CDCl}_{3}\right): \delta$ (ppm) $0.17(\mathrm{t}, J=7.1 \mathrm{~Hz}, 3 \mathrm{H}), 1.11(\mathrm{t}, J=7.3 \mathrm{~Hz}, 3 \mathrm{H}), 1.65(\mathrm{~m}, 2 \mathrm{H}), 2.11(\mathrm{~m}, 2 \mathrm{H}), 3.66(\mathrm{q}, J=7.1 \mathrm{~Hz}$, $2 \mathrm{H}), 4.79(\mathrm{~d}, J=9.7 \mathrm{~Hz}, 1 \mathrm{H}), 5.25(\mathrm{q}, J=6.0 \mathrm{~Hz}, 1 \mathrm{H}), 7.52(\mathrm{~m}, 2 \mathrm{H}), 7.64(\mathrm{~m}, 2 \mathrm{H}), 8.62(\mathrm{~d}, J=$ $8.9 \mathrm{~Hz}, 2 \mathrm{H}) ;{ }^{13} \mathrm{C}-\mathrm{NMR}\left(\mathrm{CDCl}_{3}\right): \delta(\mathrm{ppm}) 12.42,13.75,18.68,37.51,61.04,67.83,125.05$, 125.09, 125.61, 125.70, 126.73, 128.30, 135.50, 182.03; MS (EI): $\mathrm{m} / \mathrm{z} 423.45\left(\mathrm{M}^{+}, 100 \%\right)$, 277.15 (22.34\%), 237.10 (18.44\%), 214.15 (14.61\%), 176.15 (13.71\%). Calcd. for $\mathrm{C}_{24} \mathrm{H}_{22} \mathrm{NO}_{4} \mathrm{Cl}$ : C, 68.00; H, 5.23; N, 3.30. Found: C, 68.27; H, 5.44; N, 3.24\%. 
Ethyl 3-(10-chloro-9-anthryl)-5-[1-hydroxy-2-phenyl-ethyl]isoxazole-4-carboxylate 3d. Yellow flakes from hexanes-ethyl acetate $(6: 1), \mathrm{mp} 123-124{ }^{\circ} \mathrm{C} ;{ }^{1} \mathrm{H}-\mathrm{NMR}\left(\mathrm{CDCl}_{3}\right): \delta 0.14(\mathrm{t}$, $3 \mathrm{H}, J=14.0 \mathrm{~Hz}), 3.44(\mathrm{~d}, 2 \mathrm{H}, J=6.5 \mathrm{~Hz}), 3.58(\mathrm{dq}, 2 \mathrm{H}, J=14.0,2.1 \mathrm{~Hz}), 4.97(\mathrm{~d}, 1 \mathrm{H}, J=8.5)$, 5.57 (dd, 1H, J=6.5, 8.5Hz), 7.32 (m, 3H), 7.38 (m, 2H), 7.50 (ddd, 2H, J=10, 5.6, 1.4Hz), 7.57 $(\mathrm{ddd}, 2 \mathrm{H}, J=9,1.25,0.6), 7.62(\mathrm{ddd}, 2 \mathrm{H}, J=10,5.6,1.4 \mathrm{~Hz}), 8.60 \mathrm{ppm}(\mathrm{ddd}, 2 \mathrm{H}, J=8.9,1.25$, $0.6 \mathrm{~Hz}) ;{ }^{13} \mathrm{C} \mathrm{NMR}\left(\mathrm{CDCl}_{3}\right): \delta 12.52,42.41,61.11,69.17,112.05,122.02,125.13,125.17,125.76$, $125.78,126.73,126.81,126.85,127.17,128.34,128.36,128.62,129.70,129.71,131.18,131.22$, 131.27, 135.98, 160.12, 162.45, 180.01 ppm; MS: m/z 471.16 (M+), $380.15\left(\mathrm{M}^{+}-\mathrm{PhCH}_{2}\right), 306.05$ $\left(\mathrm{M}^{+}-\mathrm{PhCH}_{2}-\mathrm{COOC}_{2} \mathrm{H}_{5}\right), 278.05,176.10,91.05$. Calcd. for $\mathrm{C}_{28} \mathrm{H}_{22} \mathrm{NO}_{4} \mathrm{Cl}: \mathrm{C}, 71.26 ; \mathrm{H}, 4.70 ; \mathrm{N}$, 2.97. Found: C, 71.33; H, 4.52; N, 2.99\%.

Ethyl 3-(10-chloro-9-anthryl)-5-[2-hydroxypropyl]isoxazole-4-carboxylate 3e. Yield 64\%. $[\alpha]^{20}{ }_{589} 0.000^{\circ}\left(c=0.79, \mathrm{CH}_{2} \mathrm{Cl}_{2}\right)$; m.p. $114.5-116^{\circ} \mathrm{C},{ }^{1} \mathrm{H} \mathrm{NMR}\left(\mathrm{CDCl}_{3} \delta 8.6(\mathrm{~d}, 2 \mathrm{H}), 7.65-7.58\right.$ $(\mathrm{m}, 4 \mathrm{H}), 7.50-7.45(3 \mathrm{~m}, 2 \mathrm{H}), 4.47(\mathrm{~m}, 1 \mathrm{H}), 3.67$ (q, $J=7.2 \mathrm{~Hz}, 2 \mathrm{H}), 3.51-3.48(\mathrm{dd}, 2 \mathrm{H}), 2.59$ (d, $1 \mathrm{H}), 1.44(\mathrm{~d}, 3 \mathrm{H}), 0.25(\mathrm{t}, \mathrm{J}=7.2 \mathrm{~Hz}, 3 \mathrm{H}) ;{ }^{13} \mathrm{C}-\mathrm{NMR}, \delta .177 .94,162.77,160.90,132.04,132.02$, $131.98,129.61,129.34,129.18,127.61,127.56,127.28,126.67,126.66,126.24,126.14,125.94$, 123.29, 113.32, 67.49, 61.35, 61.23, 37.65, 24.54, 24.41, 13.6, 13.48; MS (EI) m/z 176(17.42), 214 (15.37), 227 (11.02), 237 (17.75), 253 (11.97), 277 (29.08), 278 (18.55), 279 (12.86), 375 (30.25), $408 \quad\left(\mathrm{C}_{23} \mathrm{H}_{19}{ }^{35} \mathrm{ClNO}_{4,100}(\mathrm{M}-1)^{+}\right), \quad 410 \quad\left(\mathrm{C}_{23} \mathrm{H}_{19}{ }^{37} \mathrm{ClNO}_{4}, \quad 46.54 \quad(\mathrm{M}+1)^{+}\right), \quad 411$ $\left(\mathrm{C}_{23} \mathrm{H}_{20}{ }^{37} \mathrm{ClNO}_{4}, 62.25(\mathrm{M}+2)^{+}\right)$.

Ethyl 3-(10-chloro-9-anthryl)-5-[2-hydroxy-2-phenyl-ethyl]isoxazole-4-carboxylate 3f. Yield $79 \%,[\alpha]^{20}{ }_{589}+0.2465^{\circ}\left(c=0.0155\right.$, EtOH); m.p. 119-121 ${ }^{\circ} \mathrm{C},{ }^{1} \mathrm{H}-\mathrm{NMR}\left(\mathrm{CDCl}_{3}\right) \delta .8 .6(\mathrm{~d}, 2 \mathrm{H})$, 7.63-7.28 (m, 6H), 5.45-5.39 (m, 1H), 3.88-3.73 (dd, 2H), 3.67 (q, J=7.1 Hz, 2H), $2.95(\mathrm{~d}, 1 \mathrm{H})$, $0.31(\mathrm{t}, J=7.1 \mathrm{~Hz} 3 \mathrm{H}) ;{ }^{13} \mathrm{C}-\mathrm{NMR} \delta .176 .25,161.10,159.98,142.74,131.14,131.09,128.69$, $128.297,128.291,128.20,126.74,126.70,126.65,126.56,125.84,125.82,125.67,125.06$, 122.36, 112.65, 72.54, 60.48, 37.08, 12.78. MS (EI) m/z 77 (13.45), 79 (14.72), 105 (19.34), 163 (10.69), 176 (14.33), 214 (12.65), 277 (23.69), 319 (17.48), 365 (44.89), 471 (100, M ), 472 $\left(35.78,(\mathrm{M}+1)^{+}\right), 473\left(37.49(\mathrm{M}+2)^{+}\right)$. Calcd. for $\mathrm{C}_{28} \mathrm{H}_{22} \mathrm{ClNO}_{4}$ : C, 71.26; $\mathrm{H}, 4.70 ; \mathrm{N}, 2.97$. Found: C, 71.08; H, 4.74; N, 2.84\%.

Ethyl 5-[2-hydroxy-2-phenyl-ethyl]-4-(2,5,5-trimethyl-1,3-dioxan-2-yl)isoxazole-3carboxylate 3g. Yield 91\%, yellowish oil, $[\alpha]_{\mathrm{D}}{ }^{25}=+6.9^{\circ},\left[c=1.0, \mathrm{CH}_{2} \mathrm{Cl}_{2}\right]^{1} \mathrm{H}-\mathrm{NMR} \delta 0.60(\mathrm{~s}$, $3 \mathrm{H}), 1.15(\mathrm{~s}, 3 \mathrm{H}), 1.35(\mathrm{t}, J=7.18 \mathrm{~Hz}, 3 \mathrm{H}), 1.46(\mathrm{~s}, 3 \mathrm{H}), 2.62 \mathrm{~d}, J=3.59 \mathrm{~Hz}, 1 \mathrm{H}), 3.12$ - $3.40(\mathrm{~m}$, $6 \mathrm{H}), 4.36(\mathrm{q}, J=7.18 \mathrm{~Hz}, 2 \mathrm{H}), 5.21(\mathrm{~m}, 1 \mathrm{H}), 7.25-7.35(\mathrm{~m}, 5 \mathrm{H}) .{ }^{13} \mathrm{C}-\mathrm{NMR} \delta 13.8,21.7,22.3$, 29.4, 29.6, 35.9, 62.4, 71.6, 71.8, 96.0, 115.3, 125.5, 128.0, 128.5, 143.0, 156.2, 161.5, 167.6. Calcd for $\mathrm{C}_{21} \mathrm{H}_{27} \mathrm{NO}_{6}$ : C, 64.77; H, 6.99; N, 3.60. Found: C, 64.47; H, 6.98; N, 3.42\%.

Ethyl 5-[2-(4-chlorophenyl)-2-hydroxy-ethyl]-4-(2,5,5-trimethyl-1,3-dioxan-2-yl)-isoxazole3-carboxylate 3h. Yield 83\%, colorless solid, mp. $86-88{ }^{\circ} \mathrm{C},[\alpha]_{\mathrm{D}}{ }^{25}=+13.7^{\circ} ;{ }^{1} \mathrm{H}-\mathrm{NMR} \delta 0.63$ $(\mathrm{s}, 3 \mathrm{H}), 1.16(\mathrm{~s}, 3 \mathrm{H}), 1.37(\mathrm{t}, J=7.18 \mathrm{~Hz}, 3 \mathrm{H}), 1.54(\mathrm{~s}, 3 \mathrm{H}), 2.36(\mathrm{~d}, J=3.59 \mathrm{~Hz}, 1 \mathrm{H}), 3.14$ $3.18(\mathrm{~m}, 6 \mathrm{H}), 4.39$ (q, $J=7.18 \mathrm{~Hz}, 2 \mathrm{H}), 5.22(\mathrm{~m}, 1 \mathrm{H}), 7.32(\mathrm{~s}, 4 \mathrm{H}) .{ }^{13} \mathrm{C}-\mathrm{NMR} \delta 14.0,21.9$, $22.47,29.5,29.8,36.0,62.6,71.5,71.7,96.2,115.8,127.0,128.9,133.9,141.5,156.5,161.7$, 
167.3. EIMS m/z: $408\left[(\mathrm{M}-15)^{+}\right]$, 197. Calcd for $\mathrm{C}_{21} \mathrm{H}_{26} \mathrm{NO}_{6} \mathrm{Cl}: \mathrm{C}, 59.50 ; \mathrm{H}, 6.18 ; \mathrm{N}, 3.30$. Found: C, 59.56; H, 6.14; N, 3.22\%.

Diethyl 4-[5-[2-hydroxy-2-phenyl-ethyl]-3-methyl-isoxazol-4-yl]-1,4-dihydropyridine-3,5dicarboxylate 3i. Alcohol $3 \mathbf{i}$ was prepared in a similar manner to the general procedure described above, except that 2 eq. of borane-dimethyl sulfide, and the (S)-CBS-oxazaborolidine were used. Spectroscopic characteristics of $\mathbf{3 i}$ were identical to those for the product of the racemic synthesis, ${ }^{20}$ with the exception of the optical rotation $\left([\alpha]^{20} \mathrm{D}-21.8(c 0.11)\right)$. HPLC-CSP parameters: 20:1 hexanes: iso-propanol, $10 \mathrm{uL}$ injection, Chiralpak $\mathrm{AD}$ column. $47 \%$ e.e.

3-[4-(4,4-Dimethyl-5H-oxazol-2-yl)-3-methyl-isoxazol-5-yl]-1-phenyl-propan-1-ol $\mathbf{3 j}$. The alcohol (S)-3j was prepared in a similar manner by the general procedure described above, in $82 \%$ yield. Spectroscopic characteristics of $(S)-3 \mathbf{j}$ were identical to the racemate; ${ }^{19}$ colorless solid, mp. $86-88{ }^{\circ} \mathrm{C}$, with the exception of the optical rotation $[\alpha]_{\mathrm{D}}{ }^{25}=+3.6^{\circ}$. HPLC elution parameters: $254 \mathrm{~nm}$ on a Chiralcel OJ analytical column, 40:1 hexanes: EtOH, $1 \mathrm{~mL} / \mathrm{min} .89 \%$ e.e.

\section{Acknowledgements}

NRN thanks the National Institutes of Neurological Disease and Stroke for Grants NS38444 and P20RR015583. DJB, JKN, CL and KCR, acknowledge the Malcolm and Carol Renfrew Scholarship Endowment, University of Idaho. CL and KCR also thank P20RR16454. KCR acknowledges P30 NS055022.

\section{References}

1. Pevarello, P.; Amici, R.; Brasca, M. G.; Villa, M.; Varasi, M. Targets Heterocycl. Syst. 1999, 3, 301 .

2. (a) Kennedy, T. Drug Discovery Today 1997, 2, 436. (b) Hudelson, M. G.; Ketkar, N. S.; Holder, L. B. ; Carlson, T. J.; Peng, C.-C.; Waldher, B. J.; Jones, J. P. J. Med. Chem. 2008, 51,648 .

3. Thijssen, H. H. W. J. Chromatogr. 1980, 183, 339. (b) Murai, Y.; Nakagawa, T.; Yamaoka, K.; Uno, T. Chem. Pharm. Bull. 1981, 29, 3290.

4. Lakehal, F.; Dansette, P. M.; Becquemont, L.; Lasnier, E.; Delelo, R.; Balladur, P.; Poupon, R.; Beaune, P. H.; Housset, C. Chem. Res. Toxicol. 2001, 14, 694.

5. Zhang, J. Y.; Yuan, J. J.; Wang, Y.-F. ; Bible, Jr., R. H.; Breau, A. P. Drug Metab. Dispos. 2003, 31, 491.

6. Zamponi, G.; Stotz, S. C.; Staples, R. J.; Rogers, T. A.; Nelson, J. K.; Hulubei, V.; Blumenfeld, A.; Natale, N. R. J. Med. Chem. 2003, 46, 87. 
7. Han, X.; Li, C.; Mosher, M. D.; Rider, K. C.; Zhou, P.; Crawford, R. L., Fusco, W.; Paszczynski, A.; Natale, N. R. Bioorg. Med. Chem. 2009, 17, 1671.

8. Patel, S. A; Rajale, T.; O’Brien, E.; Burkhart, D. J.; Nelson, J. K.; Twamley, B.; Blumenfeld, A.; Szabon-Watola, M. I.; Gerdes, J. M.; Bridges, R. J.; Natale, N. R. Bioorg. Med. Chem. 2010, 18, 202.

9. Natale, N. R.; Mirzaei, Y. R. Org. Prep. Proced., Int. 1993, 25, 515.

10. (a) Natale, N. R.; Rogers, M. E.; Staples, R.; Triggle, D. J.; Rutledge, A. J. Med. Chem. 1999, 42, 3087. (b) Burkhart, D. J.; Zhou, P.; Blumenfeld, A.; Twamley, B.; Natale, N. R. Tetrahedron 2001, 57, 8039. (c) Han, X.; Li, C.; Rider, K. C.; Blumenfeld, A.; Twamley, B.; Natale, N. R. Tetrahedron Lett. 2002, 43, 7673.

11. Burkhart, D. J.; McKenzie, A. R.; Nelson, J. K.; Myers, K. I. ; Zhao, X.; Magnusson, K. R.; Natale, N. R. Org. Lett. 2004, 6, 1285.

12. Nelson, J. K.; Twamley, B.; Villalobos, T. J.; Natale, N. R. Tetrahedron Lett. 2008, 49, 5957. 13. Johnson, J. S.; Evans, D. A. Acc. Chem. Res. 2000, 33, 325.

14. Kim, Y. S.; Matsunaga, S.; Das, J.; Sekine, A.; Ohshima, T.; Shibasaki, M. J. Am. Chem. Soc. 2000, 122, 6506.

15. Sigman, M.; Jacobsen, E. J. Am. Chem. Soc. 1998, 120, 5315.

16. Hoppe, D.; Hintze, F.; Tebben, P. Angew. Chem. Int. Ed. Engl. 1990, 29, 1422.

17. (a) Corey, E. J.; Bakshi, R. K.; Shibata, S. J. Am. Chem. Soc. 1987, 109, 5551. (b) Corey, E. J.; Bakshi, R. K.; Shibata, S. Chen, C.; Singh, V. K. J. Am. Chem. Soc. 1987, 109, 7925. (c) Mathre, D. J.; Thompson, A. S.; Douglas, A. W.; Hoogsteen, K.; Carroll, J. D.; Corley, E. G.; Grabowski, E. J. J. J. Org. Chem. 1993, 58, 2880.

18. (a) Davis, F. A. J. Org. Chem. 2006, 71, 8993. (b) Li, C.; Twamley, B.; Natale, N. R. J. Heterocycl. Chem. 2008, 45, 259.

19. Nelson, J. K.; Burns, C. T.; Smith, M. P.; Twamley, B.; Natale, N. R. Tetrahedron Lett. 2008, 49, 3078.

20. Nelson, J. K.; Burkhart, D. J.; McKenzie, A.; and Natale, N. R. Synlett 2003, 2213.

21. Dess, D. B.; Martin, J. C. J. Am. Chem. Soc. 1991, 113, 7277.

22. Li, C.; Twamley, B.; Natale, N. R. Acta Cryst E. 2006, E62, 0854. 